\title{
Relative importance of urbanicity, ethnicity and socioeconomic factors regarding area mortality differences
}

\author{
Sijmen A Reijneveld, Robert A Verheij, Dinny H de Bakker
}

A higher mortality rate in areas with increased socioeconomic deprivation has been found in many studies. Results are difficult to compare, however, because different indicators of area deprivation have been used. USA-based studies mostly use income to measure area deprivation, ${ }^{12}$ whereas UK-based studies often use unemployment and occupational level, but never income. ${ }^{34}$ Little is known of the relative discriminatory power of these and other indicators. The aim of this study is to examine the relative importance of income and dependence on benefits when looking at small area differences in premature mortality, and the influence of other area characteristics such as ethnicity and urbanicity.

\section{Methods}

The analysis concerned differences in premature ( $<65$ years) mortality between small areas in the Netherlands (postcode sectors) of varying deprivation.
DATA

For all Dutch postcodes, data on the number of residents and of deceased in 1995 and 1996, as well as on urbanicity, ethnicity, mean income and dependence on benefits were obtained from Statistics Netherlands. For privacy reasons, postcode data on deceased and on population were rounded to multiplicates of five and background characteristics concerning less than 10 people were not obtained.

\section{ANALYSIS}

Standard Poisson regression analysis was used to determine relative differences in premature age/gender standardised mortality between postcodes, categorised by background characteristics into quintiles of almost equal population size. The analysis focused on premature $(<$ 65 years) mortality. Socioeconomic mortality differences are especially relevant if they concern such obviously premature deaths. Furthermore, above this age the unequal
TNO Prevention and Health, Department of Public Health S A Reijneveld

NIVEL Netherlands Institute of Primary Health Care R A Verheij

D H de Bakker

Correspondence to: Dr S A Reijneveld, TNO Prevention and Health, Department of Public Health, PO Box 2215, 2301 CE Leiden, the Netherlands.

Accepted for publication 16 March 1999
Table 1 Differences in premature mortality for various indicators of postcode deprivation in 1995 and 1996: number of deceased aged 0-64 years, number of person years, relative risk (RR) after adjustment for age and gender and after additional adjustment for all other characteristics

\begin{tabular}{|c|c|c|c|c|c|c|c|c|}
\hline \multirow[b]{2}{*}{ Variable } & \multirow[b]{2}{*}{ Deceased } & \multirow{2}{*}{$\begin{array}{l}\text { Person years } \\
(\times 1000) \neq\end{array}$} & \multicolumn{3}{|c|}{ Age/gender adjusted ${ }^{\star} \dagger$} & \multicolumn{3}{|c|}{$\begin{array}{l}\text { Adjusted for age/gender } \\
\text { and all other characteristics }\end{array}$} \\
\hline & & & $R R$ & $95 \% \mathrm{C}$ & & $R R$ & $95 \% \mathrm{C}$ & \\
\hline \multicolumn{9}{|l|}{ Urbanicitys } \\
\hline lowest $(<540$ addresses $)$ & 9765 & 5202 & 1 & & & 1 & & \\
\hline 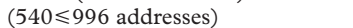 & 9580 & 5188 & 1.32 & 1.28 & 1.36 & 1.23 & 1.18 & 1.27 \\
\hline (996 $\leqslant 1464$ addresses) & 9680 & 5233 & 1.38 & 1.34 & 1.43 & 1.21 & 1.17 & 1.26 \\
\hline (1464 $\leqslant 2332$ addresses) & 10610 & 5207 & 1.51 & 1.47 & 1.56 & 1.26 & 1.21 & 1.32 \\
\hline highest ( 2332 addresses and over) & 11505 & 5214 & 1.54 & 1.48 & 1.60 & 1.24 & 1.18 & 1.31 \\
\hline \multicolumn{9}{|l|}{ Ethnicity } \\
\hline lowest $(<1 \%)$ & 7900 & 4196 & 1 & & & 1 & & \\
\hline$(1 \leqslant 2 \%)$ & 10195 & 5484 & 1.23 & 1.19 & 1.27 & 1.11 & 1.08 & 1.15 \\
\hline$(2 \leqslant 4 \%)$ & 9720 & 5309 & 1.29 & 1.25 & 1.33 & 1.09 & 1.05 & 1.13 \\
\hline$(4 \leqslant 8 \%)$ & 10620 & 5525 & 1.41 & 1.36 & 1.45 & 1.14 & 1.09 & 1.19 \\
\hline highest ( $8 \%$ and over) & 12705 & 5531 & 1.58 & 1.52 & 1.64 & 1.16 & 1.10 & 1.21 \\
\hline \multicolumn{9}{|l|}{ Mean income $e^{\star \star}$} \\
\hline highest (> dfl 32400 ) & 9390 & 5624 & 1 & & & 1 & & \\
\hline$(>$ dfl $30550-32400)$ & 8990 & 5182 & 1.03 & 1.00 & 1.06 & 1.04 & 1.01 & 1.07 \\
\hline (> dfl 29 100-30 550) & 10130 & 5234 & 1.09 & 1.06 & 1.13 & 1.07 & 1.03 & 1.10 \\
\hline$(>$ dfl $27500-29100)$ & 9815 & 4751 & 1.14 & 1.11 & 1.18 & 1.07 & 1.03 & 1.10 \\
\hline lowest (dfl 27500 and lower) & 12815 & 5254 & 1.36 & 1.31 & 1.41 & 1.09 & 1.04 & 1.13 \\
\hline \multicolumn{9}{|l|}{ Dependent on benefitstt } \\
\hline lowest $(<14 \%)$ & 6360 & 4428 & 1 & & & 1 & & \\
\hline$(14 \leqslant 17 \%)$ & 7655 & 4483 & 1.15 & 1.11 & 1.19 & 1.14 & 1.10 & 1.18 \\
\hline$(17 \leqslant 21 \%)$ & 10700 & 5690 & 1.26 & 1.22 & 1.30 & 1.18 & 1.14 & 1.23 \\
\hline$(21 \leqslant 28 \%)$ & 12900 & 6110 & 1.43 & 1.38 & 1.48 & 1.29 & 1.24 & 1.34 \\
\hline highest ( $28 \%$ and over) & 13525 & 5334 & 1.70 & 1.64 & 1.77 & 1.47 & 1.40 & 1.55 \\
\hline
\end{tabular}

*Adjusted for age $(0,1-4,5-9, \ldots, 60-64$ years), gender and their interactions. †These age/gender adjusted results concern only postcodes with non-missing values for all four measures. We separately assessed whether these analyses would yield different results if all postcodes with a non-missing value for each separate measure were included. This yielded no differences for ethnicity, mean income and dependence on benefits. However, for urbanicity, RRs are generally higher in this case: 1.59 (1.54, 1.64$), 1.71$ (1.65, $1.76), 1.92(1.86,1.99)$ and $1.92(1.85,2.00)$, respectively. $\ddagger$ Number of residents on 1 January in 1995,1996 (twice) and 1997 according to the Population Register, divided by two. \$Average number of addresses in a $1 \mathrm{~km}$ circle around every address in the postcode (1995). $\mid$ Proportion of residents who have been born in the (former) Dutch colonies Surinam and Dutch Antilles or in Turkey or Morocco, or who have at least one parent to whom this applies (1995). ${ }^{\star}$ Mean income after taxation by earner according to income tax data regarding all residents with income during the entire year 1994. ††Proportion of residents aged 16-64 years who mainly depended on benefits (welfare, unemployment and long term disability for work) in 1994.

Source for data on urbanicity, ethnicity, income and benefits: Statistics Netherlands. Key figures four digit postcodes 1995. Voorburg/Heerlen: CBS, 1997. 
spread of nursing homes confounds analyses of area differences. ${ }^{5}$ The analysis was limited to postcodes for which all deprivation data were available. Thus it concerned 51140 deaths over 26 million person years in 2679 postcodes. Because of missing data, we excluded 1279 postcodes, mostly industrial areas, comprising 1750 deaths over 880 thousand person years.

\section{Results}

Premature mortality, adjusted for age/gender, was higher in less favourable quintiles of the Dutch population for all characteristics studied $(\mathrm{p}<0.001)$, and the increase was always monotonic. Area mortality differences were largest when regarding the percentage of residents dependent on benefits, and smallest when regarding mean income by earner. Adjustment for the other characteristics decreases relative mortality risks by deprivation. Regarding urbanicity, and to a lesser degree regarding income and ethnicity, remaining differences mainly occur between the reference category and the rest (table 1 ).

\section{Discussion}

The results of this analysis show that both urbanicity, ethnicity and socioeconomic characteristics of areas are associated with mortality. Dependence on benefits shows larger (age/ gender adjusted) mortality differences than mean income, ethnicity and urbanicity, however.

Regarding income, it might be inferred that the area mean is a poor indicator because it can be highly affected by relatively few very high incomes. Results regarding the proportion of earners in the lowest $40 \%$ incomes per postcode are almost identical, however. Only for its least favourable quintile, the relative risk after adjustment for the other area characteristics is somewhat higher $(1.15 ; 95 \% \mathrm{CI} 1.10$, 1.21) than regarding mean income. This cannot be explained by a larger income inequality in these postcodes (results not shown).

Mortality risks by deprivation category show a clear dose response regarding deprivation. If the least favourable quintile is split up in two parts, its most unfavourable half again shows a higher mortality rate (results not shown), which confirms this dose response.

The results of this study have strong implications for international comparisons of area mortality differences, assuming that indicators such as income and dependence on benefits have a similar meaning in most countries. Studies based on mean income ${ }^{125}$ will tend to underestimate area mortality differences compared with studies based on dependence on benefits. ${ }^{3-5}$ The results also clearly show the poor health status in deprived areas.

Funding: this study was financially supported by the Dutch Association of General Practitioners (LHV) and by the Dutch Association of Health Insurance Companies (ZN).

Conflicts of interest: none.

1 Kennedy BP, Kawachi I, Prothrow-Stith D. Income distribution and mortality: cross sectional ecological study of the Robin Hood index in the United States. BMF 1996;312:1004-7.

2 Kaplan GA, Pamuk ER, Lynch JW, et al. Inequality in income and mortality in the United States: analysis of morality and potential pathways. BMF 1996;312:999-1003, 1253

3 Eames M, Ben-Shlomo Y, Marmot MG. Social deprivation and premature mortality: regional comparison across England. BMF 1993;307:1097-102.

4 Bentham G, Eimermann J, Haynes R, et al. Limiting long term illness and its associations with mortality and indicators of social deprivation. $\mathcal{F}$ Epidemiol Community Health 1995;49 (suppl 2):S57-64.

5 Reijneveld SA, Gunning-Schepers LJ. Age, socioeconomic status, and mortality at the aggregate level. I Epidemiol Community Health 1994;48:146-50 